\title{
Vantagens e desvantagens da utilização de peles-verdes em edificações residenciais em Porto Alegre segundo seus moradores
}

\author{
Advantages and disadvantages of using green walls in \\ residential buildings in Porto Alegre in the view of their \\ dwellers
}

\author{
Mariene Valesan \\ Beatriz Fedrizzi \\ Miguel Aloysio Sattler
}

\section{Resumo

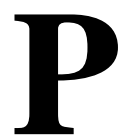

ele-verde (trepadeiras recobrindo fachadas de uma edificação, muro ou outro elemento vertical) é uma técnica de baixo impacto ambiental e com benefícios para a edificação e seu entorno. O presente trabalho analisa peles-verdes encontradas em edifícios residenciais em Porto Alegre, a partir da percepção de seus moradores, como os objetivos de gerar um registro da utilização dessa técnica e de discutir suas principais vantagens e desvantagens. A metodologia de pesquisa valeu-se de entrevistas em profundidade, estruturadas por questionários, aplicadas junto a moradores de 38 edificações (unifamiliares e multifamiliares) revestidas por peles-verdes. As pelesverdes analisadas são do tipo autoaderentes, utilizando-se das espécies Ficus pumila e Parthenocissus tricuspidata. Os entrevistados confirmaram como principais vantagens da técnica o embelezamento da paisagem, a integração do ambiente urbano e da natureza, os efeitos positivos para o bem-estar do homem e a melhoria da temperatura interna das edificações. A principal desvantagem citada

Mariene Valesan Núcleo Orientado para a Inovação da Edificação

Escola de Engenharia Universidade Federal do Rio Grande do Sul Av. Osvaldo Aranha, 99,

$3^{\circ}$ andar, Centro Porto Alegre - RS - Brasil CEP $90035-190$

Tel.: (51) 3316-3900 E-mail: valesan.arq@gmail.com

Beatriz Fedrizzi Núcleo Orientado para a Inovação da Edificação

Escola de Engenharia Universidade Federal do Rio Grande do Sul E-mail: beatrizfedrizzi@terra.com.br

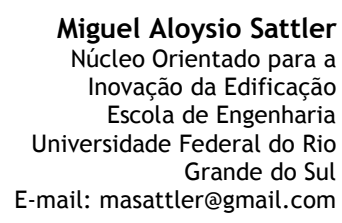

Miguel Aloysio Sattler Núcleo Orientado para a Inovação da Edificação Escola de Engenharia Universidade Federal do Rio Grande do Sul

E-mail: masattler@gmail.com

Recebido em 15/04/2010 Aceito em 20/07/2010 foi o trabalho de manutenção do revestimento vegetal. Assim, esta pesquisa indica que a pele-verde é uma técnica que tem o potencial de melhorar o ambiente urbano $\mathrm{e}$, por isso, o desenvolvimento de pesquisa sobre esse revestimento torna-se necessário.

Palavras-chave: Pele-verde. Percepção ambiental. Conforto ambiental. Vegetação. Edificações.

\section{Abstract}

Green walls (climbing plants that cover the facades of a building, walls or any other vertical elements) is a technique that produces low environmental impact and brings benefits to the building and its surroundings. This study analyzes green walls found in residential buildings in Porto Alegre, considering the perception of their dwellers, aiming to produce a record of the use of this technique, and to point out its main advantages and disadvantages. The research methodology used was a series of in-depth interviews, in which a structured questionnaire was applied to dwellers of 38 buildings (comprised of one or more housing units) covered by green walls. The analyzed green walls are self-clinging climbers, of the species Ficus pumila and Parthenocissus tricuspidata. The dwellers confirmed, as main advantages of the technique, the aesthetic improvement of the landscape, the integration between urban environment and nature and also the positive effects on the wellbeing of humans and on the internal temperatures of the building. The main disadvantage cited was the necessary maintenance work. Therefore, this study suggests that green wall is a technique that has the potential of improving the urban environment, and, for that reason, further studies on this type of covering are recommended.

Keywords: Green wall. Environmental perception. Environmental comfort. Vegetation. Buildings. 


\section{Introdução}

Conforme Kehl et al. (2008), as atuais preocupações ambientais da sociedade definem a necessidade de produtos ambientalmente saudáveis e, por isso, a edificação sustentável tem-se mostrado o novo produto da construção civil, em concordância com os princípios do desenvolvimento sustentável. O uso da vegetação é uma das opções para que as construções tornemse menos danosas ao meio ambiente, pois se trata de um elemento natural capaz de gerar benefícios notáveis às características térmicas de um local, amenizando a radiação solar mediante o sombreamento dos galhos e folhas, e controlando a temperatura por meio da transpiração do vegetal (SATTLER, 2004). Outros pontos positivos proporcionados pelo contato com a vegetação são o bem-estar físico e mental do homem, o incentivo à criatividade e ao desenvolvimento infantil e a redução do estresse.

A diversidade de características e benefícios vinculados à vegetação demonstra a versatilidade $\mathrm{e}$ as vantagens de sua aplicação junto ao ambiente construído. Entre essas aplicações tem-se a "peleverde", técnica na qual trepadeiras recobrem as fachadas de uma edificação, muro ou outro elemento vertical. Algumas vantagens dessa solução são o isolamento térmico e a diminuição da incidência de raios solares diretamente nas alvenarias, com a consequente redução dos gastos com energia para resfriamento do ambiente, além de benefícios psicológicos e estéticos.

Considerando as vantagens potenciais do uso de peles-verdes e o pouco conhecimento documentado sobre sua aplicação (KÖHLER, 2008; WONG et al., 2009), este trabalho almeja colaborar com a produção científica sobre pelesverdes. O objetivo principal desta pesquisa é analisar as peles-verdes encontradas em edifícios residenciais em Porto Alegre, a partir da percepção de seus moradores, como forma de gerar um registro da utilização dessa técnica e de suas principais vantagens e desvantagens. Pretende-se, também, contribuir para a formação de um banco de dados sobre peles-verdes e avaliar o nível de satisfação dos usuários quanto à técnica.

\section{Peles-verdes}

\section{Definição e Histórico}

Segundo Dunnett e Kingsbury (2004), é denominado pele-verde o revestimento de alvenarias ou outras estruturas verticais por meio do desenvolvimento em sua superfície de vegetação autoaderente ou com auxílio de suportes, em cuja base as raízes do vegetal estão em contato direto com o solo ou com outro tipo de substrato.

Suas origens são pouco conhecidas. Pode-se supor que tal solução poderia ser encontrada já nos primeiros assentamentos permanentes do homem. Köhler (2008) afirma haver uma longa tradição no uso de plantas ornamentais junto às edificações, principalmente na Europa, sendo a técnica, portanto, bem conhecida. No início do século XX, dois movimentos da Arquitetura foram responsáveis pela valorização das peles-verdes: o movimento Art-Noveau (movimento que valorizava a integração da natureza com as edificações) e o movimento das Cidades-Jardim (SHARP et al., 2008). A partir dos anos 30, houve decadência no uso de trepadeiras, pois a necessidade de podas e demais cuidados regulares desestimulavam seu uso (DUNNETT; KINGSBURY, 2004).

Atualmente, a pele-verde é considerada uma técnica coerente com os princípios de sustentabilidade para o ambiente construído. $\mathrm{Na}$ Alemanha, no final dos anos 70, artistas como Hundertwasser defendiam o uso desse revestimento como uma das estratégias de projeto para edifícios ecológicos (KÖHLER, 2008). Grandes cidades, tais como Londres, na Inglaterra, Seattle, nos Estados Unidos, e Toronto, no Canadá, implantaram nos últimos anos políticas de incentivo ao uso de peles-verdes, telhados verdes e demais formas de vegetação, como forma de aumentar a superfície vegetada em suas áreas urbanas e, assim, minimizar seu impacto ambiental (DESIGN FOR LONDON, 2008; PECK et al., 2007; SHARP et al., 2008).

\section{Tipos de pele-verde}

De acordo com as características das espécies utilizadas, as peles-verdes podem ser divididas em duas diferentes classes: as autoaderentes e as com necessidade de suporte.

\section{Autoaderentes}

Este caso está representado pelos revestimentos com trepadeiras com capacidade autônoma de fixação, ou seja, capazes de se aderir às superfícies por meio de raízes adventícias ou gavinhas ramificadas (Figura 1). As espécies autoaderentes mais comuns são: Ficus pumila L. (Família Moraceae), Hedera helix L. (Família Araliaceae) e Parthenocissus tricuspidata (Siebold \& Zucc.) Planch. (Família Vitaceae). 


\section{Com necessidade de suporte}

São as soluções de pele-verde nas quais é necessária a instalação de um suporte ao longo do qual a trepadeira ou o arbusto irá se desenvolver (Figura 2). Os suportes podem variar quanto ao material usado e também quanto à disposição. Há tanto as tradicionais treliças de madeira e bambu quanto as treliças metálicas, as telas e os cabos de aço. Incluem-se no grupo de espécies vegetais de peles-verdes com necessidade de suporte as trepadeiras escandentes, as trepadeiras volúveis e os arbustos escandentes.

\section{Vantagens}

\section{Efeitos sobre a temperatura interna das edificações}

A vegetação em fachada age como um revestimento isolante, mantendo uma camada de ar permanente entre a folhagem e a alvenaria, o que cria uma película que envolve o edifício e é capaz de reduzir a energia necessária, tanto para aquecer como para resfriar os ambientes internos (PECK $e t$ al., 2007; SHARP et al., 2008). McPherson, Simpson e Livingston (1989) utilizaram um modelo com um quarto do tamanho real de uma edificação, com uma linha de arbustos disposta a $50 \mathrm{~cm}$ da alvenaria, para verificar o comportamento da temperatura e dos gastos energéticos com ar condicionado em edificações com pele-verde (na cidade de Tucson, Arizona, Estados Unidos). Os resultados desse experimento indicam uma redução de $20 \%$ nos gastos energéticos do modelo revestido por vegetação. Cantuária (1995) complementa essa estimativa ao calcular reduções da ordem de $50 \%$ nos custos com ar condicionado, a partir da avaliação das temperaturas internas de uma edificação com peleverde e de uma edificação similar sem esse revestimento na cidade de Londres, Inglaterra.

Temperaturas mais amenas durante o dia e a noite foram relacionadas a coberturas vegetais em fachadas, além de terem sido evidenciadas melhorias nos níveis de conforto tanto interna quanto externamente (CANTUÁRIA, 1995; MCPHERSON; HERRINGTON; HEISLER, 1989). Köhler (2008) comenta que a redução na temperatura interna das edificações está relacionada tanto à área revestida por vegetação quanto à espessura da camada vegetal.

Segundo Cantuária (1995), o desempenho climático da edificação é significativamente afetado pela pele-verde, pois, além de serem percebidas mudanças quanto à temperatura, o ganho de calor por radiação solar, por ondas longas e por convecção, também é reduzido. Um estudo conduzido por Wong et al. (2009) simula, por meio de programas computacionais, as temperaturas médias radiantes para edificações similares com e sem pele-verde para Singapura, no norte da Indonésia. Os resultados foram de 24,01 ${ }^{\circ} \mathrm{C}$ para a edificação com vegetação aderida em todas as fachadas e de $34,39^{\circ} \mathrm{C}$ para a edificação sem vegetação.

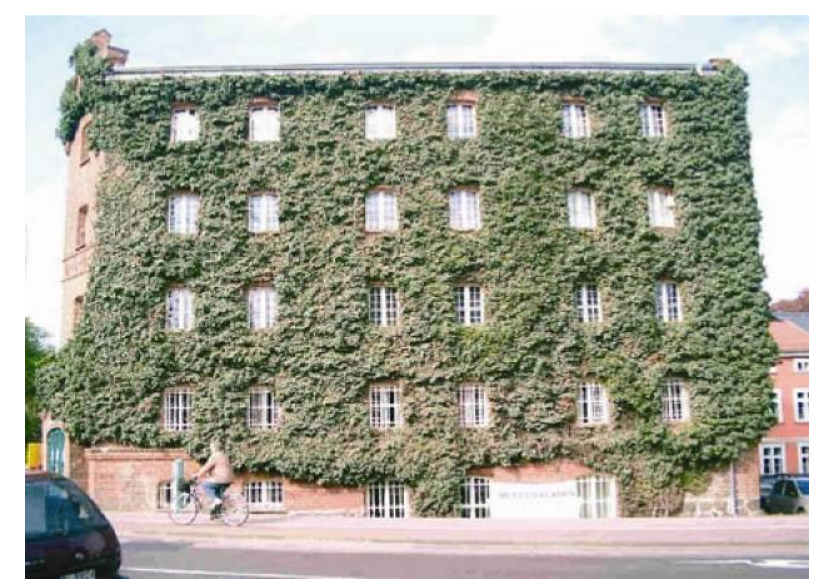

Fonte: Köhler (2008).

Figura 1 - Exemplo de pele-verde autoaderente da espécie hera inglesa (Hedera helix L.) 


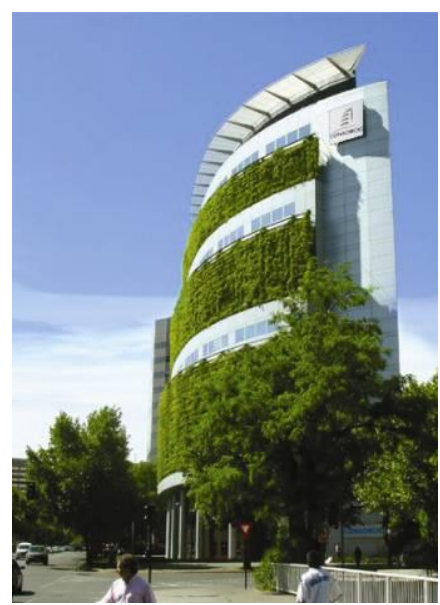

(a)

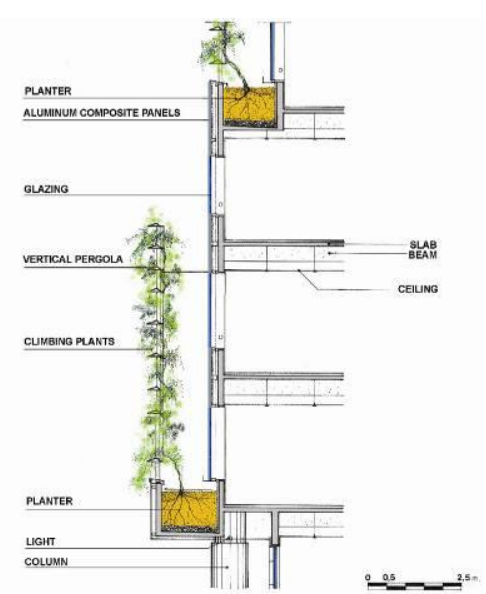

(b)

Fonte: Browne (2007).

Figura 2 - Exemplo de pele-verde com necessidade de suporte em Santiago, Chile - Edifício Consórcio (a) vista externa e (b) detalhe em corte da treliça com vegetação

Constata-se ainda que as temperaturas da alvenaria coberta por vegetação também são efetivamente menores que as da alvenaria tradicional, devido à ação da vegetação como redutor do ganho de calor da edificação (PECK et al., 2007). Eumorfopoulou e Kontoleon (2009) conduziram um estudo no qual é feito um comparativo entre medições de dados térmicos junto a dois pavimentos da fachada leste de uma mesma edificação situada na região norte da Grécia: um dos pavimentos revestido por peleverde da espécie Parthenocissus tricuspidata e outro sem revestimento vegetal. Os resultados dessas medições apontam para uma redução da temperatura da superfície externa revestida por vegetação de $5,7^{\circ} \mathrm{C}$, quando comparada à temperatura da superfície externa desprotegida, em média. Além disso, a temperatura da superfície interna da alvenaria com revestimento vegetal é, em média, $0,9^{\circ} \mathrm{C}$ menor do que a temperatura da superfície interna da alvenaria sem vegetação.

Ademais, as peles-verdes com espécies caducifólias possuem a propriedade de se adaptar às variações climáticas em curto e longo prazo, pois, de acordo com o ângulo de incidência dos raios solares e a intensidade da temperatura da primavera, as folhas são reorganizadas, inclinadas ou até mesmo tem seu brotamento antecipado. Dessa forma, a sombra adequada à edificação é fornecida também no momento adequado (CANTUÁRIA, 1995).

Além da influência quanto à temperatura, a peleverde também é responsável pela criação de barreiras para o vento, direcionando-o e fazendo com que o ar quente seja conduzido para o topo da edificação mais rapidamente. A evaporação e a transpiração são responsáveis por um poder de resfriamento adicional (SHARP et al., 2008). Já no inverno, as espécies perenes criam uma camada de ar entre a alvenaria e o ambiente, reduzindo os diferenciais de temperatura das temperaturas externas e, consequentemente, as perdas de calor da edificação por convecção (JOHNSTON; NEWTON, 1992).

Por fim, as imediações de edificações com pelesverdes também são beneficiadas pela pele-verde, pois essa cobertura evita o ganho de calor por meio da reflexão dos raios solares nas alvenarias e também reduz as temperaturas extremas do verão por meio da evapotranspiração de sua superfície foliar (SHARP et al., 2008).

\section{Controle da umidade}

Ao contrário do pensamento popular, fachadas cobertas por vegetação podem ser barreiras para a umidade excessiva de inverno, pois as folhas evitam que a água das chuvas entre em contato direto com a alvenaria (DUNNETT; KINGSBURY, 2004; JOHNSTON; NEWTON, 1992).

\section{Conservação das alvenarias}

Em relação a possíveis problemas de deterioração da edificação causados por trepadeiras, Johnston e Newton (1992) consideram isso incorreto, pois, na verdade, é observado o contrário. Em muitos casos, a cobertura vegetal serve como proteção da alvenaria, tornando sua deterioração consideravelmente mais lenta que uma parede exposta às intempéries (chuvas fortes, granizo e raios ultravioleta) e às variações bruscas de temperatura (DUNNETT; KINGSBURY, 2004; SHARP et al., 2008). 


\section{Controle da poluição}

Assim como as árvores, peles-verdes podem reter partículas de poeira do ar, que são mantidas na superfície foliar do vegetal, deixando, assim, de circular livremente pela atmosfera (KÖHLER, 2008; PECK et al., 2007), além de absorver o gás carbônico do ar para efetuar o processo de fotossíntese (SHARP et al., 2008). Além disso, os metais pesados encontrados na água da chuva também são absorvidos pelo vegetal (DUNNETT; KINGSBURY, 2004).

\section{Benefícios à fauna local}

O plantio de trepadeiras pode ser bastante benéfico para espécies de pássaros e insetos, tais como borboletas e mariposas (SHARP et al., 2008). Muitas trepadeiras também proveem abrigo, local para que determinados pássaros possam construir seus ninhos e proteção para que alguns insetos façam seus casulos (DUNNETT; KINGSBURY, 2004; KÖHLER, 2008).

\section{Embelezamento da paisagem urbana}

Peles-verdes são uma excelente solução para incrementar espaços urbanos com vegetação (Figura 3), principalmente aqueles em que o plantio de árvores está impossibilitado pela falta de espaço. As atrativas mudanças ao longo das estações no aspecto de determinadas espécies de trepadeiras em fachada tornam a paisagem mais interessante para o usuário e para a população em geral (GRUB, 1986; PECK et al., 2007). Assim, visuais mais interessantes podem ser criados em vizinhanças em que a qualidade estética das edificações seja insatisfatória ou pouco atrativa, tais como depósitos industriais e garagens, ou em longas superfícies de parede cega (SHARP et al., 2008). Dunnett e Kingsbury (2004) também sugerem o uso de trepadeiras em áreas em que o tráfego de veículos e as ações de vandalismo possam causar danos aos elementos verticais.

\section{Desvantagens}

Em geral, problemas de projeto e plantio da peleverde são os responsáveis por suas desvantagens, principalmente quanto ao uso de espécies inapropriadas. Os principais danos possíveis à edificação devido à instalação da pele-verde são explicados, segundo Dunnett e Kingsbury (2004) e Sharp et al. (2008), pelos seguintes motivos:

(a) dimensionamento incorreto do suporte da vegetação, tanto em relação ao porte do vegetal quanto às cargas incidentes na estrutura;

(b) escolha inapropriada da forma de fixação do suporte à edificação;

(c) falta de espaço para o vegetal se desenvolver, principalmente quanto à espessura dos galhos;

(d) falhas e baixa qualidade do revestimento, que podem acarretar danos à edificação ainda que a escolha do vegetal e do suporte tenha sido apropriada; $\mathrm{e}$

(e) manutenção insuficiente para o porte da vegetação, resultando em autoestrangulamento do espécime, desenvolvimento deficiente ou desordenado, ou, ainda, gavinhas modificadas e outros elementos de fixação aderindo-se a áreas não planejadas, tais como esquadrias.

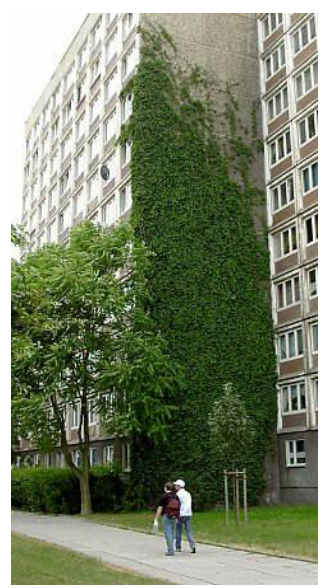

(a)

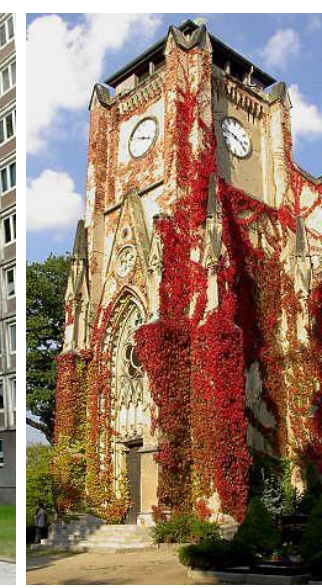

(b)

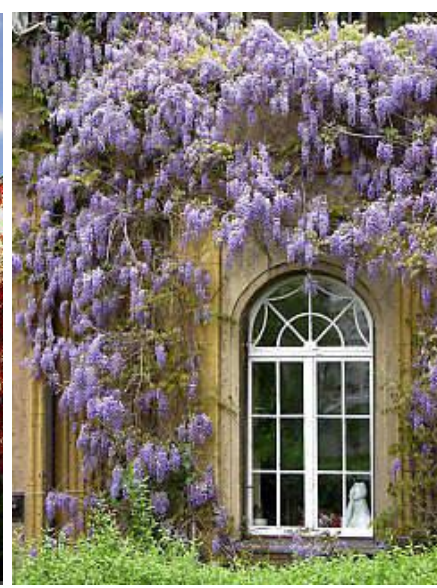

(c)

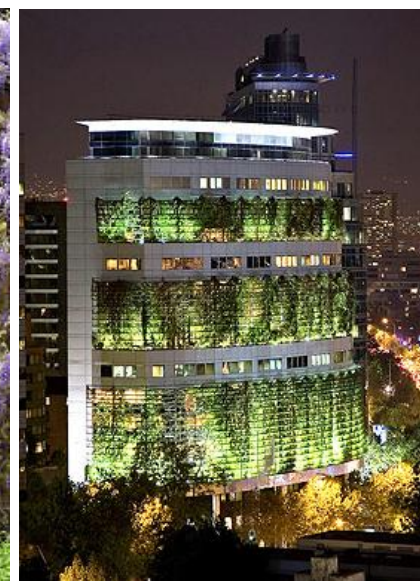

(d)

Fonte: (a), (b) e (c) Fassaden Gruen (2008) e (d) Browne (2007).

Figura 3 - Exemplos de peles-verdes que demonstram a variabilidade de cores - (a) do verde (b) aos tons de vermelho - e (c) efeitos estéticos - (d) devido à presença de flores ou ao efeito ocasionado pela luz através de suas folhas 


\section{Manutenção}

A manutenção periódica da pele-verde é essencial para o sucesso desse revestimento. Dunnett e Kingsbury (2004) citam que os principais cuidados a serem observados são a condução dos galhos e fixação deles à estrutura, quando necessário, e a poda dos galhos jovens que crescem em direção a áreas indesejadas. Dunnett e Kingsbury (2004) explicam que as trepadeiras são adaptadas a diversos tipos de solo, tendo como únicas exigências que esse seja um solo fértil e, em geral, úmido e protegido de raios solares excessivos. Já quanto à necessidade de irrigação, Johnston e Newton (1992) afirmam que esta irá variar de acordo com a espécie escolhida para plantio. Quanto à altura que pode ser revestida por vegetação, Dunnett e Kingsbury (2004) sugerem que a altura máxima prevista para uma pele-verde seja da ordem de $24 \mathrm{~m}$, apesar de algumas trepadeiras serem capazes de atingir alturas mais elevadas $(30 \mathrm{~m})$. $\mathrm{O}$ plantio em floreiras de sacadas poderia estender essa altura máxima, desde que houvesse suprimento de nutrientes adequados.

\section{Metodologia}

Este trabalho é resultante de uma dissertação de mestrado desenvolvida durante 2008 e 2009. Ele consiste de um levantamento de opinião envolvendo dados de caráter prioritariamente qualitativo. A pesquisa foi conduzida junto aos moradores de edificações com peles-verdes em Porto Alegre, como forma de investigar as propriedades desse tipo de revestimento. Para isso, analisou-se a percepção dos moradores de residências com tal característica, a fim de se identificar seus principais aspectos e sua aceitação.

Porém, devido ao fato de que, durante o levantamento das edificações a serem analisadas, não foi possível identificar as edificações que já possuíram peles-verdes mas que as retiraram por algum motivo, os resultados representam, em geral, a opinião de moradores satisfeitos com essa técnica e referem-se a edificações em que esse revestimento teve uma aplicação bem-sucedida. Os casos em que as peles-verdes foram retiradas não foram contemplados, exceto por uma edificação, na qual o revestimento foi removido ao longo do desenvolvimento da pesquisa.

O trabalho iniciou-se com uma pesquisa piloto (SATTLER; VALESAN, 2008), tendo sido de grande importância para gerar um entendimento inicial sobre o tema, o que facilitou as tomadas de decisões quanto à segunda etapa de investigação.

Utilizaram-se como critérios para a seleção das edificações a serem analisadas as seguintes características: ser uma edificação de uso residencial em Porto Alegre que possuísse peleverde como revestimento externo em pelo menos uma parte relevante de suas fachadas; e ter moradores disponíveis para participar da pesquisa. A amostra foi definida pela possibilidade de acesso aos moradores e pela autorização das entrevistas, buscando a pesquisa da totalidade dos exemplares relevantes.

Para análise das opiniões dos moradores quanto ao revestimento, foram conduzidas entrevistas estruturadas mediante um questionário-base. As entrevistas foram gravadas e posteriormente transcritas. Em alguns casos, depoimentos espontâneos de outros moradores e funcionários das residências também foram registrados, a fim de ilustrar o trabalho. Além das entrevistas, realizouse um levantamento fotográfico da edificação e dos detalhes relativos à pele-verde.

O questionário-base para as entrevistas em profundidade continha perguntas abertas e fechadas, organizadas em categorias (dados gerais, dados do entrevistado, satisfação do usuário quanto à residência e caracterização da peleverde). Para melhor analisar os dados obtidos, as respostas às perguntas abertas foram divididas em itens, segundo análise de dados recomendada por Bardin (2004). Ao final, contabilizou-se o percentual de respondentes que citaram itens pertencentes a cada uma das categorias identificadas. É importante esclarecer que, apesar de haver uma quantificação das respostas, o foco da análise é prioritariamente qualitativo. Portanto, os percentuais encontrados se referem apenas aos respondentes da pesquisa, não sendo representativos da opinião de todos os moradores de edificações com peles-verdes. Outro esclarecimento pertinente é que, para muitas das perguntas abertas, obteve-se mais de uma resposta por entrevistado. Portanto, o somatório dos percentuais de cada resposta ultrapassa o valor de $100 \%$.

\section{Resultados}

Foram encontrados, em Porto Alegre, 49 exemplares residenciais com pele-verde como revestimento de ao menos uma de suas fachadas, sendo 7 multifamiliares e 42 unifamiliares, num total de 80 domicílios. Ao final da coleta de dados, obtiveram-se 52 entrevistas, 31 delas realizadas com moradores de residências unifamiliares e 21 com moradores de apartamentos das 7 edificações multifamiliares. Foram pesquisadas, por meio do levantamento da opinião de seus moradores, pelesverdes de 38 edificações $(77 \%$ do total de exemplares residenciais encontrados). Além disso, 
16 exemplares de outros usos e 9 exemplares desocupados foram encontrados, somando, por fim, 74 edificações.

A idade de $60 \%$ dos entrevistados, ou seja, 31 indivíduos, concentrou-se entre 40 e 59 anos, e a renda familiar mensal informada de $66 \%$ deles (34 entrevistados) variou entre 3 e 12 mil reais (Tabela 1). Notou-se predominância de entrevistados com alto índice de escolaridade, pois $77 \%$ deles (40 entrevistados) possuíam ensino superior completo, dos quais $9 \%$, ou seja, 5 respondentes, informaram também possuir pós-graduação. Trata-se, portanto, de indivíduos com alto poder aquisitivo e alto grau de instrução. Quanto às ocupações, verificou-se primazia de atividades relacionadas às artes visuais (arquitetura e artes plásticas), somando 12 entrevistados, ou $23 \%$. O tempo de moradia nos domicílios foi de 17,5 anos em média, sendo o tempo mínimo de moradia informado de 3 anos, e o máximo, de 45 anos.

As duas espécies de maior recorrência nas edificações residenciais analisadas (Figura 4) foram Ficus pumila, em 26 edificações (32 entrevistas), e Parthenocissus tricuspidata, em 11 (19 entrevistas). Uma edificação possuía ambas as espécies (1 entrevista).

Dos 52 entrevistados, 35 moradores (67\%) souberam informar quando suas peles-verdes haviam sido plantadas. $\mathrm{O}$ tempo de plantio informado variou entre 2 e 32 anos, e a média de idade foi de 12,5 anos para as peles-verdes de Ficus pumila e de 17 anos para as de Parthenocissus tricuspidata. A média total foi de 14 anos de presença de revestimento vegetal. Além disso, a maioria dos revestimentos vegetais estudados encontrava-se em bom estado de conservação.

\begin{tabular}{|c|c|c|c|}
\hline & & Percentual & $N^{\circ}$ de entrevistados \\
\hline \multirow{6}{*}{ 旁 } & 17 a 29 anos & $4 \%$ & 2 \\
\hline & 30 a 39 anos & $10 \%$ & 5 \\
\hline & 40 a 49 anos & $29 \%$ & 15 \\
\hline & 50 a 59 anos & $31 \%$ & 16 \\
\hline & 60 a 69 anos & $15 \%$ & 8 \\
\hline & 70 anos ou mais & $11 \%$ & 6 \\
\hline \multirow{5}{*}{ 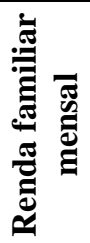 } & Entre R\$ $1.000,00$ e $\mathrm{R} \$ 3.000,00$ & $7 \%$ & 4 \\
\hline & Entre R\$3.000,01 e R\$ 6.000,00 & $33 \%$ & 17 \\
\hline & Entre $\mathrm{R} \$ 6.000,01$ e $\mathrm{R} \$ 12.000,00$ & $33 \%$ & 17 \\
\hline & Mais de $\mathrm{R} \$ 12.000,00$ & $17 \%$ & 9 \\
\hline & Não informado & $10 \%$ & 5 \\
\hline
\end{tabular}

Tabela 1 - Idade e renda familiar mensal informada pelos moradores de edificações com pele-verde em Porto Alegre (dados referentes ao $2^{\circ}$ semestre de 2008)

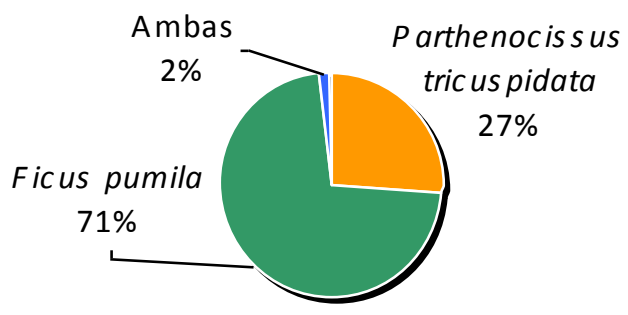

Figura 4 - Percentuais das diferentes espécies vegetais das peles-verdes encontradas em Porto Alegre em 2008, considerando apenas as edificações residenciais analisadas 


\section{Sobre a satisfação dos usuários quanto à pele-verde}

Ao exporem suas opiniões sobre a pele-verde, 42 entrevistados $(80 \%)$ afirmaram estarem satisfeitos com o revestimento. Alguns moradores complementaram sua resposta descrevendo as vantagens da técnica. Já outros respondentes comentaram sobre opiniões favoráveis de terceiros sobre a vegetação. No entanto, para 6 depoentes, ou $12 \%$ dos entrevistados, a pele-verde é motivo de insatisfação e transtornos. Por fim, $8 \%$, ou 4 moradores, preferiram manter-se neutros, não se manifestando nem favoráveis, nem contrários ao revestimento. Percebe-se, portanto, que o elevado número de pessoas satisfeitas com a técnica é um dado que reforça suas vantagens. No entanto, também deve ser considerado o fato de esta pesquisa avaliar apenas as peles-verdes mantidas por seus moradores, devido à impossibilidade de identificação das residências nas quais a pele-verde havia sido retirada. Portanto, usuários que possuíam pele-verde em suas residências, mas a removeram por estarem insatisfeitos, não foram consultados neste estudo.

\section{Vantagens indicadas pelos moradores}

Indicaram-se diversos pontos positivos da utilização de peles-verdes (Figura 5). Apenas 8\%, ou 4 moradores, não identificam nenhuma vantagem desse revestimento. As vantagens citadas pelos moradores são apresentadas a seguir.

\section{Embelezamento da paisagem urbana e da edificação}

O ganho estético para a edificação e, consequentemente, para a paisagem urbana foi a vantagem mais recorrente durante as entrevistas, tendo sido apontado por 41 moradores (79\%). Além disso, um destes entrevistados acrescentou que tal revestimento pode ser entendido como um recurso para edificações sem qualidades estéticas. A pele-verde, nesses casos, funcionaria como uma solução simples e econômica para o embelezamento da edificação. Uma moradora, arquiteta, utilizou a pele-verde como elemento de projeto na ampliação de sua residência, a fim de harmonizar a edificação antiga e a área nova, buscando, com isso, uma coerência formal entre as partes (Figura 6). A utilização de pele-verde nas fachadas existentes, bem como a utilização de tijolo à vista nas novas fachadas, diferencia os volumes, mas também é capaz de integrá-los, uma vez que essas duas matérias-primas remetem à natureza. Já outros moradores ilustraram suas respostas informando sua preferência pelas variações ao longo do ano e pelas cores das folhas nos meses de outono e inverno (no caso da Parthenocissus tricuspidata) ou pelo aspecto verde ao longo do ano todo (no caso da Ficus pumila) das peles-verdes de suas moradias.

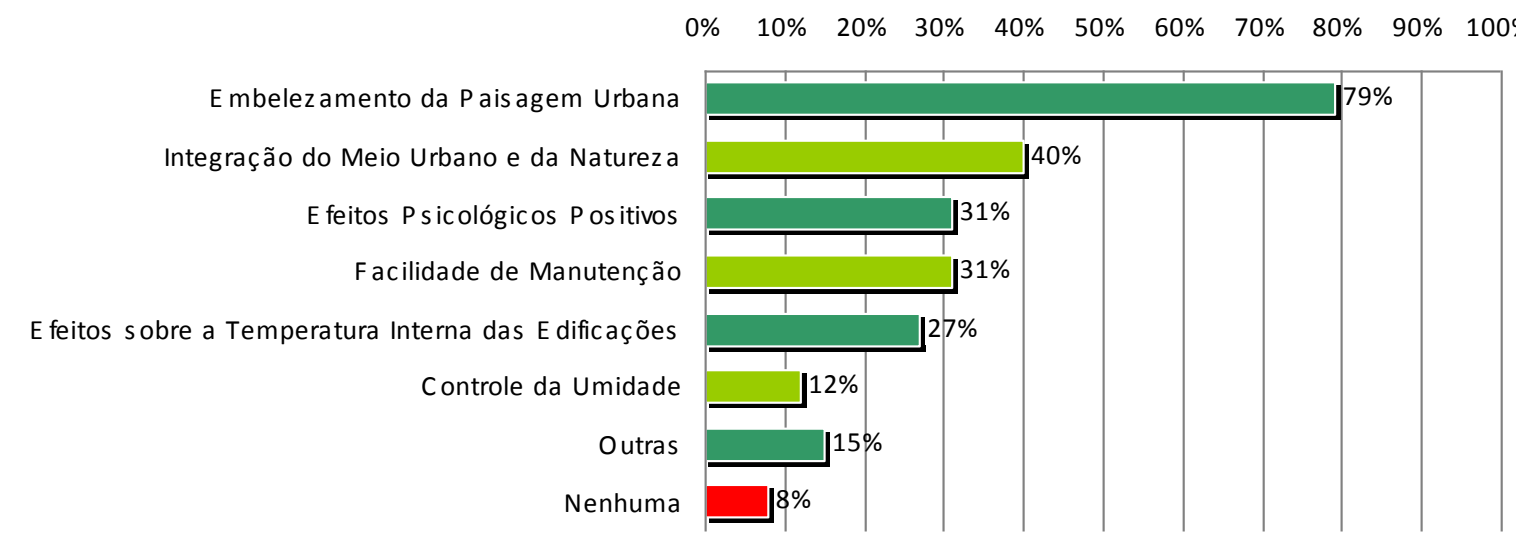

Figura 5 - Vantagens da aplicação de peles-verdes citadas pelos moradores de edificações com peleverde em Porto Alegre em 2008 


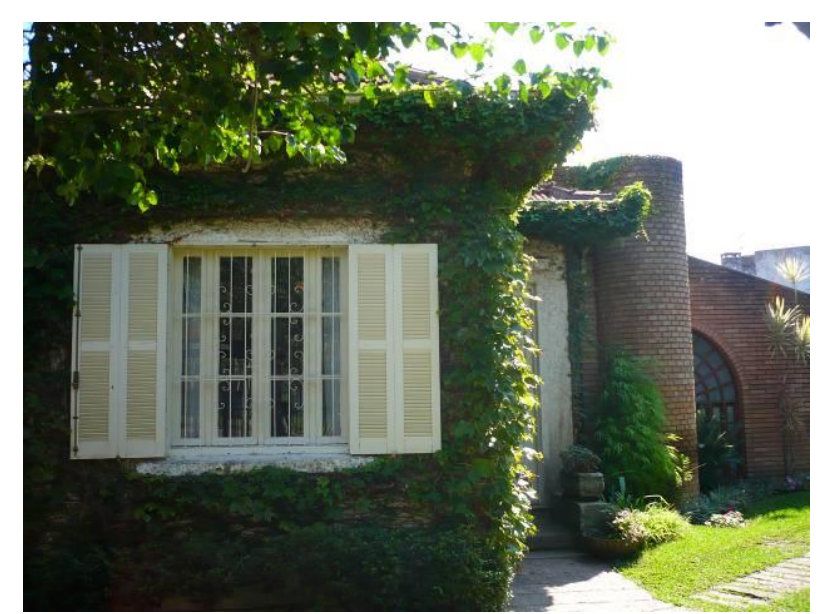

Figura 6 - Edificação estudada em Porto Alegre, na qual a parte antiga foi revestida por pele-verde da espécie Parthenocissus tricuspidata como forma de se harmonizar à ampliação da residência, em tijolo à vista (2008)

\section{Integração do meio urbano e da natureza}

O fato de a vegetação em fachada ser um meio pelo qual ocorre uma aproximação entre natureza e meio urbano foi citado por $40 \%$, ou 21 respondentes, como um aspecto positivo. Alguns destes moradores citaram termos relacionados ao ganho de superfície vegetada do espaço, por exemplo, "sensação de amplitude do verde", "ser envolvido pelo verde" ou "jardim pelas paredes". As vantagens paisagísticas da pele-verde também foram citadas por um morador, que ressaltou ser essa uma opção para pequenos jardins, que não teriam espaço para plantio de espécies de maior porte, tais como árvores.

Além dessas vantagens, a redução da poluição atmosférica foi citada por um respondente e os benefícios à fauna urbana também foram comentados. Os animais considerados mais frequentes devido à pele-verde foram pássaros, lagartixas e borboletas. Alguns moradores descreveram episódios nos quais a presença de animais junto ao revestimento tornou a vivência na residência mais agradável. Porém, apesar de a presença de vida animal junto à pele-verde ter sido percebida pelos moradores, é preciso investigar se isso se deve exclusivamente à pele-verde ou ao fato de os ambientes dos entornos dessas edificações terem, em geral, vegetação abundante.

\section{Efeitos psicológicos positivos}

Os benefícios psicológicos foram apontados por 16 entrevistados (31\%). Estes descreveram tais benefícios evocando sentimentos de satisfação, bem-estar e tranquilidade, além de acreditarem que os ambientes da residência tornam-se mais aconchegantes e agradáveis pela presença da peleverde. Nota-se que o sentimento de biofilia, ou seja, os efeitos psicológicos positivos propiciados pelo contato com a natureza, é percebido pelos moradores, demonstrando, assim, o potencial de benefícios ao bem-estar do ser humano que as peles-verdes podem proporcionar. Como complemento aos depoimentos, Ulrich (1993) também comenta sobre diversas pesquisas nas quais os resultados demonstram que sentimentos de relaxamento, paz e outros estados emocionais positivos são benefícios associados à exposição a paisagens que contenham elementos naturais. Além disso, a redução do estresse, da fadiga mental e de sentimentos negativos, tais como agressividade e medo, também foi verificada em indivíduos em contato com paisagens naturais (ULRICH, 1993; BERTO, 2005).

\section{Facilidade de manutenção}

Para $31 \%$, ou 16 moradores, a manutenção da residência é facilitada pela presença desse revestimento. A característica marcante nesse caso é a não necessidade de pintura ou de reparos na pintura existente, pois a vegetação dificulta a percepção das imperfeições da alvenaria e protegea de atos de vandalismo, tais como pichações.

\section{Efeitos sobre a temperatura interna das edificações}

Os benefícios ao conforto térmico da residência foram citados por 14 entrevistados, ou $27 \%$. Destes, 7 afirmaram notar a propriedade de isolamento térmico da pele-verde e outros 7 acreditam que a temperatura no verão é mais amena em ambientes revestidos por vegetação. Um morador também descreveu as vantagens térmicas da pele-verde para o verão e o inverno, afirmando que esse revestimento cria uma camada de ar isolante ao longo das fachadas, a qual reduz as variações de temperatura nos ambientes internos. 


\section{Controle da umidade}

Seis moradores $(12 \%$ dos respondentes) declararam existir redução da umidade da residência ou da alvenaria devido à presença da vegetação nas fachadas. Alguns deles notam tal fato pela ausência de mofo nos ambientes durante o inverno ou percebem que a água da chuva é absorvida pela trepadeira, evitando a transferência de umidade para a alvenaria.

\section{Desvantagens indicadas pelos moradores}

A seguir são apresentadas as desvantagens da peleverde, conforme opinião dos moradores das residências investigadas (Figura 7). É interessante ressaltar que 9 entrevistados, ou seja, 17\%, estão tão satisfeitos com a técnica que não identificam nenhuma desvantagem de sua aplicação.

\section{Necessidade de manutenção}

A manutenção foi a desvantagem mais lembrada, por 37 respondentes, ou seja, $71 \%$. Em algumas entrevistas, foram citados problemas relacionados ao desenvolvimento do vegetal, tais como o desenvolvimento acelerado ou desordenado, a necessidade de controle da área revestida pelo vegetal, ou, ainda, o fato de haver um tempo, em geral alguns anos, entre o plantio do espécime vegetal e a plena constituição dele como um revestimento uniforme. A necessária poda dos galhos indesejados foi o aspecto mais lembrado. Para alguns, tal característica não constitui uma desvantagem significativa, mas, ainda assim, é um fator que demanda mais atenção se comparado a outros tipos de revestimento. Por fim, um morador explica que a necessidade de manutenção se torna uma característica negativa do revestimento, pois nem sempre os profissionais contratados são aptos para executar uma poda correta.

\section{Danos à edificação}

Em 12 entrevistas (23\%) citaram-se possíveis danos à edificação em decorrência da pele-verde. Esses danos podem ocorrer, segundo os depoimentos, na pintura, no revestimento, na alvenaria ou na estrutura.

Os danos à pintura estão relacionados à aderência da vegetação na edificação. Tal fato ocasionaria, no futuro, maior dificuldade e maior custo para pintura da residência, no caso de se optar pela remoção da pele-verde. Porém, se considerarmos tal revestimento como permanente na residência, essa afirmativa perde a relevância. Uma vez que a edificação foi planejada para receber a pele-verde, não há necessidade de pintura da alvenaria (SATTLER; VALESAN, 2008), consequentemente o reparo desta torna-se nulo.

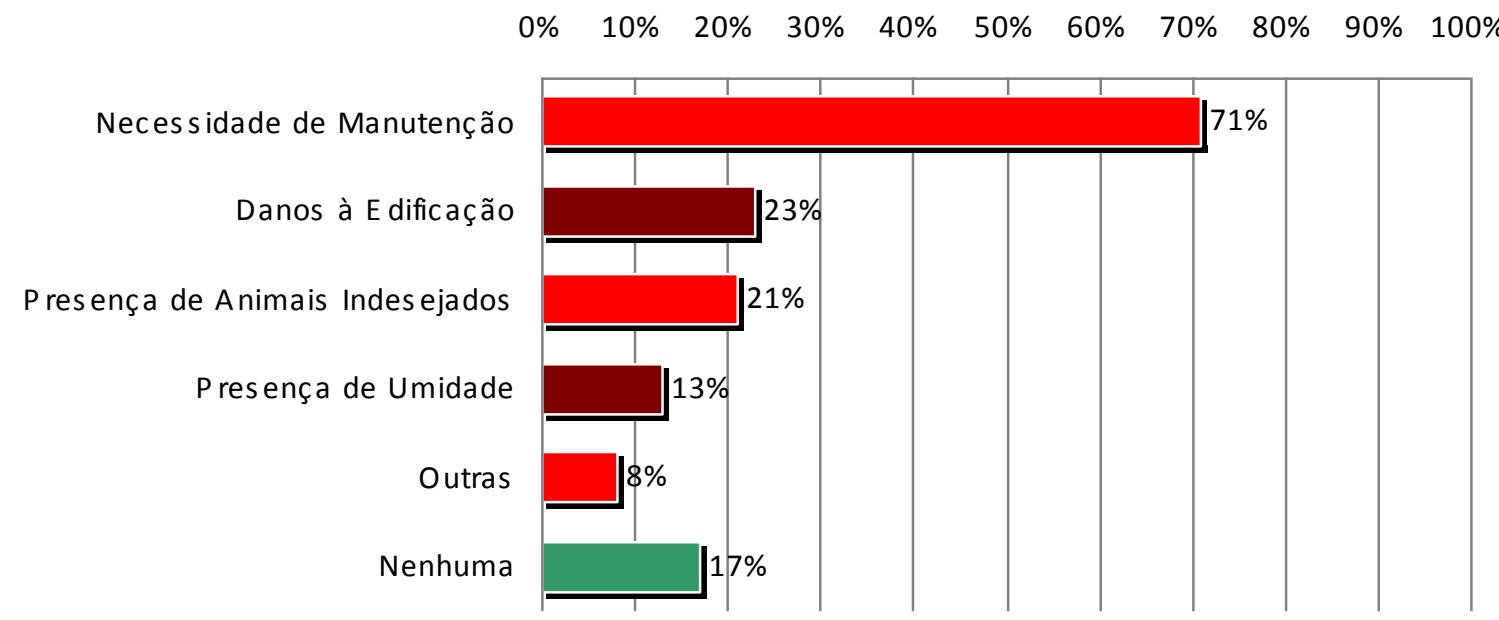

Figura 7 - Desvantagens da aplicação de peles-verdes citadas pelos moradores das edificações com pele-verde em Porto Alegre em 2008 
Alguns entrevistados acreditam que esse tipo de revestimento danificaria a alvenaria, ocasionando fissuras, desprendimento de parte do revestimento ou deterioração em função da umidade. Porém, além de esses problemas não serem confirmados pela bibliografia, muitos desses moradores não identificaram problemas dessa ordem em sua própria residência. Das 38 edificações entrevistadas, apenas 9 apresentaram problemas dessa natureza. Ainda assim, o fato de terem sido constatados esses danos não significa que a peleverde seja a responsável por eles. Em alguns casos, os revestimentos danificados eram bastante antigos, com problemas de execução e de impermeabilização, ou estavam em orientações solares desfavoráveis.

Nota-se que a falta de informações sobre a técnica leva os moradores, e também a população em geral, a tomar relatos envolvendo as peles-verdes que não estão efetivamente documentados e descritos em trabalhos científicos como verdadeiros. Portanto, será preciso uma investigação mais detalhada para esclarecimento das causas de tais problemas e para indicação da efetiva responsabilidade da pele-verde nos danos relatados.

\section{Presença de animais indesejados}

Para $21 \%$, ou seja, 11 entrevistados, alguns animais indesejados são atraídos pela pele-verde, o que se constitui em uma desvantagem da técnica. Os animais citados foram lesmas, formigas, mosquitos, abelhas e ratos.

O caso das lesmas ocorreu em apenas uma residência e necessita de confirmação quanto a sua relação com a trepadeira. A presença de formigas é relacionada à pele-verde por uma moradora. Porém, esta salienta que tal problema é pouco perturbador e que não justificaria a retirada da vegetação. Já uma terceira entrevistada nota a presença de mosquitos junto à trepadeira, principalmente nas noites de verão ao regar o jardim. Mais uma vez, tal presença não é considerada grave, sendo considerada uma característica de qualquer tipo de vegetação encontrada em ambientes urbanos. No caso da espécie Parthenocissus tricuspidata, existem fortes indícios de que no verão suas flores sejam atrativas para determinada espécie de abelha. Enquanto alguns moradores indicaram tal característica como positiva, uma moradora considera a presença de abelhas incômoda.

Além disso, foram relatados dois episódios em que se constatou a presença de ratos na residência. Apesar da proliferação dos ratos não ter sido relacionada às peles-verdes, sua presença parece ter facilitado o acesso de tais animais ao interior da edificação, inclusive nos pavimentos mais elevados. Ou seja, em ambientes nos quais o problema de infestação de roedores é conhecido, a pele-verde pode se transformar em um meio facilitador do contato desses animais com os moradores. Portanto, nesses casos, a decisão por esse revestimento deve levar em consideração tal aspecto.

\section{Presença de umidade}

A presença de umidade mais acentuada no interior das residências devido à pele-verde foi indicada por 7 respondentes (13\%) como uma desvantagem da técnica. No entanto, em muitos desses relatos ficou evidente que a umidade está presente em vários pontos da residência, e não somente na fachada revestida por vegetação. Percebeu-se ainda que a concentração dos sinais de umidade muitas vezes ocorria junto ao piso das residências, tratando-se evidentemente de uma umidade proveniente do subsolo, que surgia nos ambientes internos por meio da capilaridade dos elementos de fundação e da deficiente impermeabilização junto ao solo. Além disso, a afirmação de que pelesverdes retêm umidade junto às alvenarias é contrária ao que afirmam diversos autores (para eles, a pele-verde atua como uma proteção para a umidade) e também a outros depoimentos de moradores, que evidenciam redução de umidade interna devido à presença do revestimento vegetal.

\section{Considerações finais}

As análises efetuadas neste trabalho demonstram que a pele-verde é uma técnica de grandes vantagens e também de excelente potencial para a qualificação do ambiente urbano. Uma evidência dessa afirmativa é a acentuada satisfação dos moradores com a técnica e com suas residências. No entanto, como os casos em que o revestimento vegetal nas alvenarias foi testado, rejeitado e, por fim, retirado não puderam ser devidamente identificados e representados nesta pesquisa, é preciso ponderar que os achados deste trabalho referem-se apenas aos casos bem-sucedidos de aplicações de peles-verdes em edificações residenciais e que as opiniões dos entrevistados representam, de modo geral, a categoria de moradores satisfeita com esse revestimento.

Foram encontradas, no total, 74 edificações com pele-verde em ao menos uma de suas fachadas (considerando-se as edificações residenciais e os exemplares de outros usos ou desocupados). Pelo fato de os 49 exemplares residenciais analisados utilizarem basicamente peles-verdes do tipo autoaderente, o estudo acabou limitado à 
investigação das características de apenas duas espécies: Parthenocissus tricuspidata e Ficus pumila. Há uma predisposição para a utilização duradoura dessa técnica (14 anos em média), sendo a Ficus pumila a espécie mais recorrente. Os entrevistados, moradores de edificações com peleverde, possuem alto poder aquisitivo e também alto nível de escolaridade.

Para esses moradores, sentimentos de bem-estar estão relacionados com essa técnica, fato que indica uma relação entre peles-verdes e sentimentos de biofilia, ou seja, sensações positivas evocadas pelo contato com elementos naturais. Segundo indicação dos moradores, uma das vantagens da técnica é sua capacidade isolante para as variações de temperatura do meio, gerando melhorias nas condições internas de conforto tanto para o verão como para o inverno. Os benefícios também são percebidos junto à fauna local e ao controle da poluição atmosférica. O embelezamento da paisagem e o contato com a natureza também foram altamente relacionados à vegetação em fachada, confirmando o potencial da técnica como qualificador do ambiente urbano e podendo, portanto, ser amplamente difundido como argumento para aplicação desta técnica em novos locais.

Pode-se concluir, a partir dos depoimentos dos entrevistados, que a principal desvantagem da técnica refere-se à necessidade de manutenção. Temas como danos às alvenarias, presença de animais indesejados e umidade excessiva ocasionada pela pele-verde também foram mencionados. Porém, como as opiniões quanto a estes itens muitas vezes se opuseram, não é possível concluir se efetivamente existe uma influência da vegetação junto a esses e se esta seria positiva ou negativa. Por isso, são necessárias maiores investigações para o correto esclarecimento destas questões.

Nota-se, portanto, a necessidade de futuros trabalhos sobre peles-verdes, a fim de investigar os temas levantados neste trabalho e, também, aspectos ainda não estudados dessa técnica. Primeiramente, sugere-se a aplicação de entrevistas junto a moradores de edificações residenciais nas quais o revestimento vegetal em fachada tenha sido retirado, como forma de equiparar as opiniões compiladas nesta pesquisa e de investigar os motivos que ocasionaram a retirada do revestimento vegetal. Além disso, pesquisas focadas nos aspectos físicos da vegetação também seriam altamente elucidativas. Algumas possibilidades seriam medições físicas dos exemplares estudados para os itens temperatura, umidade e danos das alvenarias. Outra linha interessante de investigação seria a de estudos comparativos entre ambientes de mesmas características revestidos e não revestidos por peles-verdes, a fim de se avaliar o percentual de melhoria das questões de conforto ambiental para a região de clima subtropical úmido. Também poderiam ser conduzidas pesquisas que focassem as influências das peles-verdes no microclima urbano das imediações das edificações com tal revestimento. Dessa forma, seriam avaliadas as consequências para conforto dos espaços abertos e também para o ecossistema local. Ainda quanto às questões referentes à fauna urbana, sugere-se a investigação quanto aos animais beneficiados pela presença da pele-verde no ambiente urbano e, por fim, a monitoria de animais junto à vegetação, como forma de averiguar a existência de insetos e aracnídeos em peles-verdes.

Por fim, conforme anteriormente comentado, este estudo está focado exclusivamente nas pelesverdes autoaderentes, sendo necessários, portanto, estudos sobre as especificidades das peles-verdes com necessidade de suporte. A avaliação do potencial de utilização de espécies de trepadeiras nativas como revestimento também seria importante como forma de preservação e valorização do ecossistema local. Ainda quanto à exploração de outras espécies não estudadas neste trabalho, há a necessidade de avaliar a viabilidade do uso de espécies frutíferas junto às habitações, com o objetivo de aliar a produção alternativa de alimentos com benefícios climáticos para o ambiente e seus usuários.

\section{Referências}

BARDIN, L. Análise de Conteúdo. 3. ed.

Tradução de Luís Antero Reto e Augusto Pinheiro. Lisboa: Edições 70, 2004.

BERTO, R. Exposure to Restorative Environments Helps Restore Attentional Capacity. Journal of Environmental Psychology, London, v. 25, n. 3, p. 249-259, Sept. 2005.

\section{BROWNE, E. The "Consorcio-Santiago"}

Building 14 Years Later. Santiago de Chile: Enrique Browne y Arquitectos Asociados, 2007. Disponível em:

<http://www.ebrowne.cl/escritos/2007_consorcio_ stgo_i.pdf $>$. Acesso em: 11 jun. 2009.

\section{CANTUÁRIA, G. Microclimatic Impact of} Vegetation on Building Surfaces. 1995. $81 \mathrm{f}$. Dissertação (Mestrado em Arquitetura) Architectural Association Graduate School, London, 1995. 
DESIGN FOR LONDON. Living Roofs and

Walls: technical report: supporting London plan policy. London: Greater London Authority, 2008. Disponível em:

<http://www.designforlondon.gov.uk/uploads/med ia/5_Living_Roofs_technical_report.pdf $>$. Acesso em: 25 maio 2009.

DUNNETT, N.; KINGSBURY, N. Planting

Green Roofs and Living Walls. Portland: Timber Press, 2004.

EUMORFOPOULOU, E. A.; KONTOLEON, K. J. Experimental Approach to the Contribution of Plant-Covered Walls to the Thermal Behaviour of Building Envelopes. Building and Environment, Oxford, v. 44, n. 5, p. 1024-1038, May 2009.

FASSADEN GRUEN. Façade Greening. Leipzig, 2008. Disponível em:

<http://www.fassadengruen.de/eng/indexeng.htm>. Acesso em: 18 jun. 2008.

GRUB, H. Ajardinamientos Urbanos. Tradução de José Luis Moro Carreño. Barcelona: Gustavo Gili, 1986.

JOHNSTON, J.; NEWTON, J. Building Green: a guide to using plants on roofs, walls and pavements. London: The London Ecology Unit, 1992.

KEHL, C. et al. Percepção de Clientes Finais sobre Atributos de Desenvolvimento Sustentável para Habitações. In: ENCONTRO NACIONAL DE TECNOLOGIA DO AMBIENTE CONSTRUÍDO, 12., 2008, Fortaleza. Anais... Porto Alegre: ANTAC, 2008.

KÖHLER, M. Green Façades: a view back and some visions. Urban Ecosystems, London, v. 11, n. 4, p. 423-436, 2008.

MCPHERSON, G.; HERRINGTON, L.;

HEISLER, G. Impacts of Vegetation on Residential Heating and Cooling. Energy and Buildings, Lausanne, v. 12, n. 1, p. 41-51, Apr. 1988.

MCPHERSON, G.; SIMPSON, J.; LIVINGSTON, M. Effects of Three Landscape Treatments on Residential Energy and Water Use in Tucson, Arizona. Energy and Buildings, Lausanne, v. 13, n. 2, p. 129-138, Apr. 1989.
PECK, S. et al. Greenbacks from Green Roofs: forging a new industry in Canada. Ottawa: Mortgage and Housing Corporation, 2007. (Research Highlight. Technical Series, 01-101). Disponível em: <http://www.cmhcschl.gc.ca/odpub/pdf/62665.pdf >. Acesso em: 07 out. 2009.

SATTLER, M. A. Edificações Sustentáveis: interface com a natureza do lugar. In: MENEGAT, R.; ALMEIDA, G. (Org.). Desenvolvimento Sustentável e Gestão Ambiental nas Cidades: estratégias a partir de Porto Alegre. Porto Alegre: Editora da UFRGS, 2004. p. 259-288.

SATTLER, M. A.; VALESAN, M. Green Walls and their Contribution to Environmental Comfort: environmental perception in a residential building. In: INTERNATIONAL CONFERENCE ON PASSIVE AND LOW ENERGY ARCHITECTURE, 25., 2008, Dublin. Anais... Dublin: PLEA, 2008.

SHARP, R. et al. Introduction to Green Walls: technology, benefits \& design. Toronto: Green Roofs for Healthy Cities, 2008. Disponível em: <http://www.greenroofs.net/components/com_lms/ flash/Green\%20Walls\%20Intro\%20908b.pdf $>$. Acesso em: 08 out. 2009.

ULRICH, R. S. Biophilia, Biophobia and Natural Landscapes. In: KELLERT, S. R.; WILSON, E. (Ed.). The Biophilia Hypothesis. Washington, DC: Island: Shearwater Books, 1993. p. 73-137.

VALESAN, M. Percepção Ambiental de Moradores de Edificações Residenciais com Pele-Verde em Porto Alegre. 2009. 178 f. Dissertação (Mestrado em Engenharia) - Escola de Engenharia, Universidade Federal do Rio Grande do Sul, Porto Alegre, 2009.

WONG, N. et al. Energy Simulation of Vertical Greenery Systems. Energy and Buildings, Lausanne, v. 41, n. 12, p. 1401-1408, Dec. 2009. 